\title{
Torsional Fretting Corrosion Behaviors of the CoCrMo/Ti6Al4V Couple
}

\author{
Songquan Wang ${ }^{1, *}$, Dekun Zhang ${ }^{2, *}$, Meng Sun ${ }^{1}$, Ningning $\mathrm{Hu}^{l}$ \\ ${ }^{1}$ School of Mechatronic Engineering, JiangSu Normal University, 101\# Shanghai Road, Xuzhou \\ 221116, China \\ ${ }^{2}$ School of Materials Science and Engineering, China University of Mining and Technology, 1\# \\ University Road, Xuzhou 221116, China \\ "E-mail: wbplsz@ outlook.com' dkzhang@ cumt.edu.cn
}

doi: $10.20964 / 2018.07 .21$

Received: 5 April 2018 / Accepted: 10 May 2018 / Published: 5 June 2018

There are different forms of fretting corrosion on the fitting surface of hip prosthesis head and neck, which have an impact on the service life of the implant. In this paper, the torsional fretting corrosion experiment of CoCrMo alloy and Ti6Al4V alloy in FBS solution was simulated by simulating the head-neck taper contact mode of the hip joint. The effects of angular displacement amplitude and contact load on the wear mechanism and electrochemical corrosion properties of prosthesis materials were discussed. The results showed that the value of friction torque first increased and then tended to be stable at the taper contact interface of CoCrMo head and Ti6Al4V neck under the condition of small normal load. However, the friction torque was stable at early stage with no significant increase under larger loads. After friction, the corrosion potential of CoCrMo alloy was significantly negative and the current of the anode region was obviously increased, which showed that the corrosion tendency of materials increased. According to the results of the electrochemical corrosion test, the impedance of CoCrMo alloy after friction decreased significantly, as well as the polarization resistance. When the angle displacement amplitude $\theta=2^{\circ}$, obvious slip band could be found on the sample surface, which was badly worn and corroded under small normal load. Under larger normal load, a large number of scratches along the twisting direction appeared on the worn surface, accompanied by peeling and corrosion of the material. The relative movement of the sample surface was mainly based on partial slip.

Keywords: Torsional fretting corrosion, contact surface, CoCrMo/Ti6Al4V

FULL TEXT 
(C) 2018 The Authors. Published by ESG (www.electrochemsci.org). This article is an open access article distributed under the terms and conditions of the Creative Commons Attribution license (http://creativecommons.org/licenses/by/4.0/). 